\title{
Martensitic Transformation Induced by Cold Deformation of Lean Duplex Stainless Steel Uns S32304
}

\author{
S. S. M. Tavares ${ }^{\mathrm{a}}$, J. M. Pardal ${ }^{\mathrm{a}}$, M. R. da Silva ${ }^{\mathrm{b}}$, C. A. S. de Oliveira ${ }^{c}$ \\ aPrograma Francisco Eduardo Mourão Saboya de Pós-graduação em Engenharia Mecânica - PGMEC, \\ Escola de Engenharia, Universidade Federal Fluminense - UFF, \\ Rua Passo da Pátria, 156, Niterói, RJ, Brasil \\ ${ }^{\mathrm{b} I n s t i t u t o ~ d e ~ F i ́ s i c a ~ e ~ Q u i ́ m i c a, ~ U n i v e r s i d a d e ~ F e d e r a l ~ d e ~ I t a j u b a ́ ~-~ U N I F E I, ~ I t a j u b a ́, ~ M G, ~ B r a s i l ~}$ \\ 'Departamento de Engenharia Mecânica, Universidade Federal de Santa Catarina - UFSC, \\ Florianópolis, SC, Brasil
}

Received: April 9, 2013; Revised: September 1, 2013

\begin{abstract}
Lean duplex UNS S32304 is an austenitic ferritic stainless steel with pitting resistance equivalent number around 24-25. Its corrosion resistance is similar to AISI 316L steel, but with the advantage of a yield limit two times superior to conventional austenitic grades. Deformation induced martensitic transformations $\left(\gamma \rightarrow \varepsilon\right.$ and $\gamma \rightarrow \alpha^{\prime}$ ) have been extensively studied in austenitic steels, but few works were published about these reactions in austenitic ferritic grades. In the present work, deformation induced martensitic transformation in lean duplex UNS S32304 was investigated by means of magnetic measurements and X-ray diffraction. The curves of $\alpha$ ' martensite volume fraction against true deformation by cold rolling were constructed and compared to duplex and austenitic grades. It was found that lean duplex UNS S32304 is much more susceptible to martensitic transformation than duplex UNS S31803, which can be explained by its lower Mo and Ni contents.
\end{abstract}

Keywords: martensitic transformation, cold deformation, lean duplex stainless steel

\section{Introduction}

Austenitic ferritic are a subclass of stainless steels which have been largely used in many industrial sectors due to the high mechanical and corrosion resistance. This subclass may be divided into superduplex (SDSS), duplex (DSS) and "lean" duplex (LDSS) steels. The pitting resistance equivalent number (PRE) is used to separate SDSS from DSS. Steels with PRE $>40$ are superduplex, and those with PRE $<40$ are duplex or "lean" duplex. LDSS have lower PRE than DSS because their Mo content is very low (less than 1.0\%). A non official boundary between LDSS and DSS is the PRE number of 30.

LDSS grade UNS S32304 is an austenitic ferritic stainless steel developed in the 80's. Its corrosion resistance is similar to AISI 316L steel, but with the advantage of a yield limit two times superior to conventional austenitic grades. Compared to the DSS UNS S32205/31803 the grade $\mathrm{S} 32304$ has less $\mathrm{Mo}, \mathrm{Ni}$ and $\mathrm{N}$, which makes it cost considerably lower.

Deformation induced martensitic transformations $(\gamma \rightarrow \varepsilon$ and $\gamma \rightarrow \alpha^{\prime}$ ) have been extensively studied in austenitic steels ${ }^{1-3}$, but few works were published about these reactions in austenitic ferritic grades. Lo and $\mathrm{Lai}^{4}$ studied the magnetic properties of a SDSS 7MoPlus superduplex steel (SDSS) and found that this steel was not susceptible to martensitic transformation. On the other hand, evidences of ferromagnetic martensite formation in duplex UNS S31803 by cold rolling were found in previous works ${ }^{5,6}$. The

*e-mail: ssmtavares@terra.com.br metastability of the austenite phase is strongly influenced by chemical composition. Superduplex steel 7 MoPlus has higher Cr, Mo and Ni contents than UNS S31803, which makes the austenite phase of the superduplex grade more stable against martensitic transformation.

The stability of austenite phase is related to its chemical composition, and, thus, can also be influenced by the solution treatment temperature ${ }^{7}$. The increase of the solution temperature may decrease the austenite volume fraction as it approaches to the ferrite field. On the other hand, if the austenite volume fraction is lower, it's Ni content may be higher, which turns this phase more stable.

The aim of the present work is to investigate the deformation induced martensitic transformation in lean duplex UNS S32304 and compare to other duplex and austenitic grades.

\section{Experimental}

A $1.8 \mathrm{~mm}$ sheet of lean duplex UNS S32304 with composition shown in Table 1 was received with solution treatment at $1000{ }^{\circ} \mathrm{C}$ for 40 minutes followed by water quenching. Specimens with $15 \times 10 \times 1.8 \mathrm{~mm}^{3}$ were carefully cut with the longitudinal direction parallel to the original rolling direction of the sheet. Then, the specimens were cold rolled in the laboratory with the rolling direction parallel to their longitudinal axis. The un-deformed specimen was named LD ST (solution treated) and the deformed specimens were named LD X-Y, where $\mathrm{Y}$ is a code for the deformation applied, as shown in Table 2. 
Table 1. Chemical composition of lean duplex UNS S32304 investigated in this work (\%wt.).

\begin{tabular}{ccccccccccc}
\hline $\mathbf{C r}$ & $\mathbf{N i}$ & $\mathbf{M o}$ & $\mathbf{M n}$ & $\mathbf{S i}$ & $\mathbf{N}$ & $\mathbf{C u}$ & $\mathbf{C}$ & $\mathbf{P}$ & $\mathbf{S}$ \\
\hline 22.5 & 3.59 & 0.22 & 1.39 & 0.41 & 0.13 & 0.46 & 0.02 & 0.04 & 0.001 \\
\hline
\end{tabular}

Table 2. Specimens produced by cold rolling.

\begin{tabular}{ccc}
\hline Specimen & $\mathbf{h}_{\mathbf{f}}(\mathbf{m m})$ & True deformation $(\varepsilon)$ \\
\hline LD X-1 & 1.15 & -0.009 \\
LD X-2 & 1.01 & -0.138 \\
LD X-3 & 0.82 & -0.347 \\
LD X-4 & 0.71 & -0.491 \\
LD X-5 & 0.69 & -0.519 \\
LD X-6 & 0.41 & -1.040 \\
LD X-7 & 0.31 & -1.320 \\
LD X-8 & 0.25 & -1.535 \\
\hline
\end{tabular}

Another sample was produced by melting a small sample of lean duplex in an arc furnace. The solidification was very fast because occurred in a water cooled cooper crucible. Part of this melted material was cut for analysis (specimen LD-MELT), and other part was cold rolled with true deformation $\varepsilon=2.05$ (specimen LD-M-CR).

After rolling discs with $3.5 \mathrm{~mm}$ of diameter and $0.3 \mathrm{~mm}$ thickness were cut by electro-erosion from each specimen. Magnetization curves were obtained at room temperature in a vibrating sample magnetometer (VSM). The maximum field applied was 14,000 Oe (1.4T).

Martensite quantification was done according to the magnetic method described by Cullity and Graham ${ }^{8}$. Basically, when a paramagnetic and a ferromagnetic phase are present, the volume fraction of the ferromagnetic phase $\left(\mathrm{C}_{\text {FERRO }}\right)$ may be quantified by (Equation 1$)$ :

$$
C_{F E R R O}=\frac{m_{S}}{m_{S(i)}}
$$

Where $m_{s}$ is the magnetization saturation of the specimen analyzed and $\mathrm{m}_{\mathrm{S}(\mathrm{i})}$ is the magnetization saturation intrinsic of the ferromagnetic phase. However, it must be remembered that the lean duplex steel also contains ferrite as ferromagnetic phase. The simplification adopted in this work was to consider the $\mathrm{m}_{\mathrm{s}(\mathrm{i})}$ of martensite $\alpha^{\prime}$ equal to the $\mathrm{m}_{\mathrm{S}(\mathrm{i})}$ of ferrite $(\delta)$. The goal of produce a specimen by melting and cold rolling was to obtain a microstructure containing only ferrite and $\alpha$ ' martensite phases, whose magnetization saturation could be adopted as the $\mathrm{m}_{\mathrm{S}(\mathrm{i})}$ value used in the martensite quantification of the other specimens.

Considering that $\mathrm{C}_{\mathrm{FERRO}}=\mathrm{C}_{\alpha^{\prime}}+\mathrm{C}_{\delta}$, the quantification of martensite volume fraction $\left({\stackrel{\alpha}{\alpha^{\prime}}}_{\alpha^{\prime}}\right)$ was achieved by the difference (Equation 2):

$$
C_{\alpha^{\prime}}=C_{F E R R O}-C_{\delta}
$$

Where $\mathrm{C}_{\delta}$ could be determined in the un-deformed specimen.

Two methods for measuring the $\mathrm{m}_{\mathrm{s}}$ were adopted. In method 1 the last points of the magnetization curve $(\mathrm{M} \times \mathrm{H})$ are selected, a linear fit is performed, and the $m_{s}$ value is obtained by the extrapolation of the curve to $\mathrm{H}=0$, as shown in Figure 1. In method 2, the $\mathrm{m}_{\mathrm{s}}$ value is obtained by the extrapolation of the $\mathrm{M} \times 1 / \mathrm{H}$ to $1 / \mathrm{H}=0(\mathrm{H} \rightarrow \infty)$.

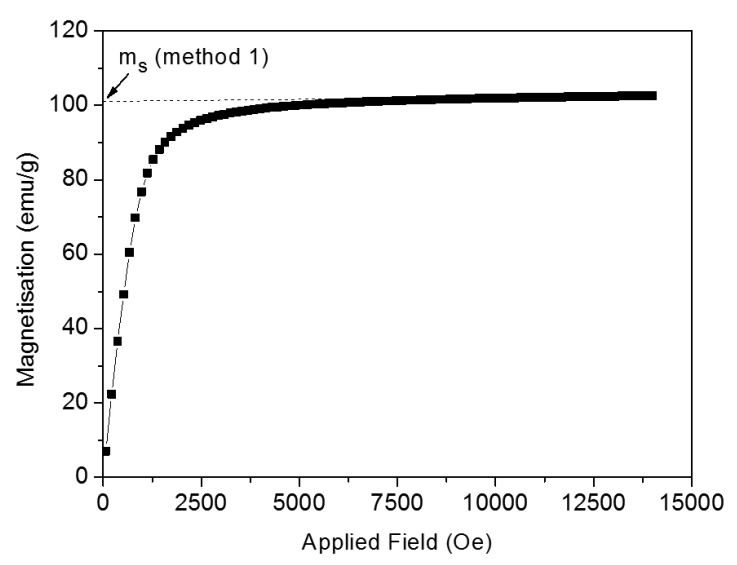

Figure 1. Magnetization curve of specimen LD X-5.

Although quantification of $\alpha^{\prime}$ in all specimens was performed by magnetic method, the microstructures of some specimens were analyzed by light optical microscopy (LOM) and X-ray diffraction (XRD). Specimens for LOM were etched with Beraha's etching $\left(20 \mathrm{~mL} \mathrm{HCl}, 80 \mathrm{~mL} \mathrm{H}_{2} \mathrm{O}\right.$ and $0.3 \mathrm{~g}$ of potassium metabissulfite). XRD was performed with $\mathrm{Cu}$ radiation $(\lambda=1.5408 \AA)$.

\section{Results and Discussion}

Figure 2 shows the microstructure of lean duplex UNS S32304 as received with the annealing treatment (specimen named LD ST). The ferrite and austenite volume fractions measured according to ASTM E-562 ${ }^{[9]}$ were $0.52 \pm 0.03$ and $0.48 \pm 0.03$, respectively. Figure 3 shows the microstructure of specimen LD X-2 with portions of martensite $\alpha$ ' inside the austenite island (see circles in the image).

XRD patterns of specimens LD ST, LD X-2 and LD X-5 are shown in Figure 4. The peaks of ferrite $(\delta)$ and $\alpha$ ' martensite are coincident. The intensity of austenite peaks decrease with the progress of cold deformation. Peaks of martensite $\varepsilon$ were not found in any deformed specimen.

Figure 5 shows the comparison of magnetization curves of specimens deformed. The increase of magnetization saturation with the increase of cold deformation is due the martensitic transformation $\gamma \rightarrow \alpha$ '.

The microstructure of specimen LD-MELT is shown in Figure 6. A predominantly ferritic structure, with some austenite islands, was obtained. The magnetization saturation of this specimen was $136.7 \mathrm{emu} / \mathrm{g}$ (method 1) or $138.1 \mathrm{emu} / \mathrm{g}$ (method 2). The cold deformation applied to produce specimen LD-M-CR increased the magnetization saturation to $140.2 \mathrm{emu} / \mathrm{g}(\operatorname{method} 1)$ or $140.7 \mathrm{emu} / \mathrm{g}$ (method 2). These values were adopted as the intrinsic magnetization saturation of martensite $\alpha^{\prime}$ and ferrite $\delta$.

The magnetization saturation of specimen LD-ST (un-deformed) was $70.8 \mathrm{emu} / \mathrm{g}$ by method 1 and $73.8 \mathrm{emu} / \mathrm{g}$ 
by method 2 . The amount of ferrite present in the un-deformed specimen can be estimated from these magnetic methods and compared to that measured by quantitative metallography, as shown in Table 3.

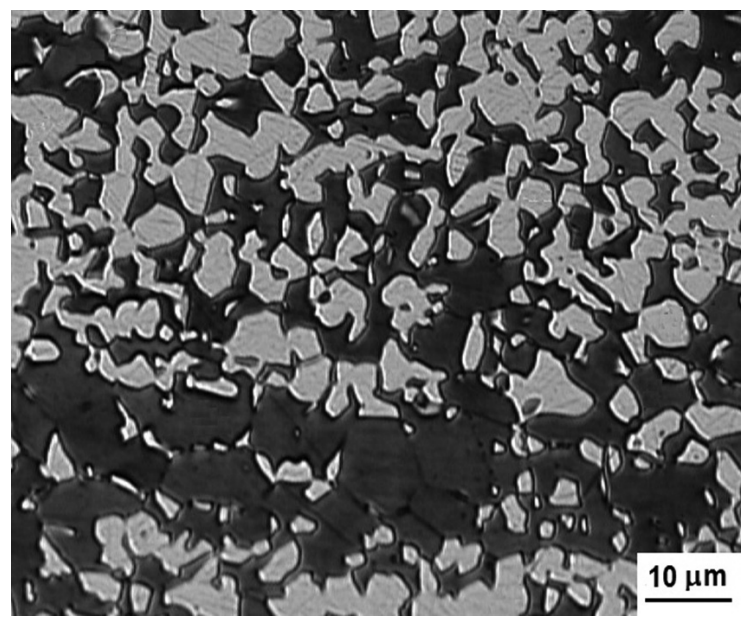

Figure 2. Microstructure of specimen LD ST.

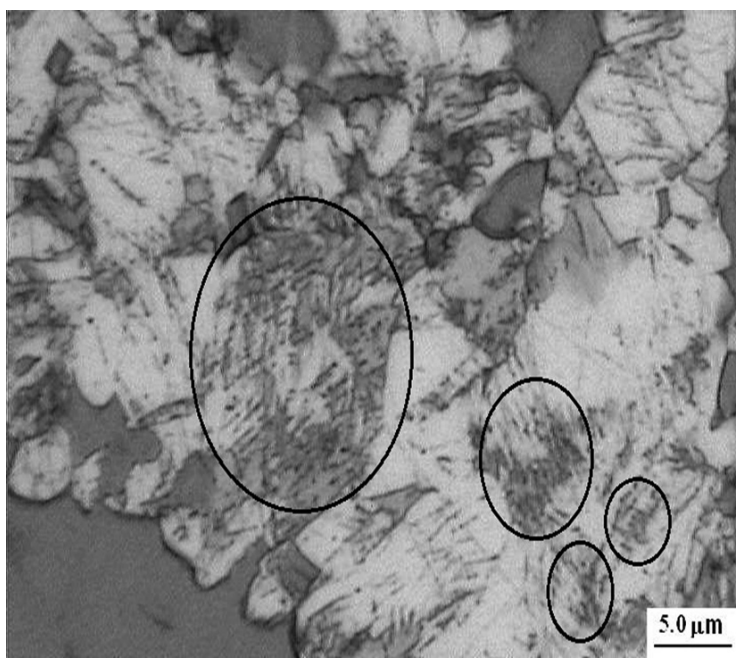

Figure 3. Microstructure of specimen LD X-2. Martensite portions inside the austenite island are highlighted by circles.

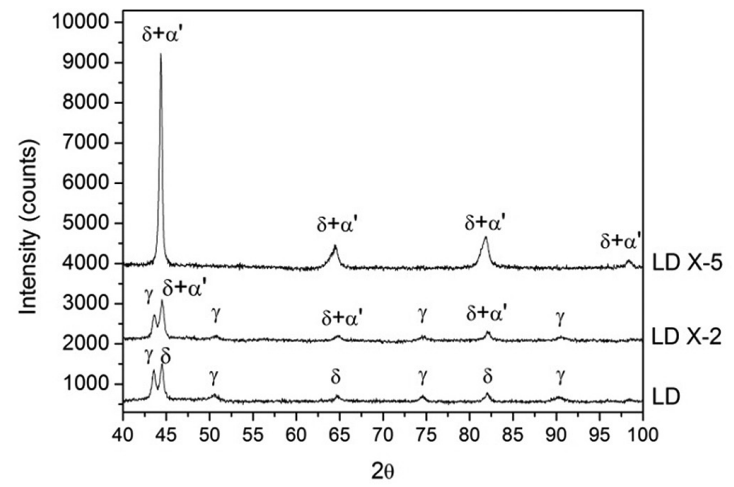

Figure 4. X-ray diffraction patterns of specimens LD ST, LD X-2 and LD X-5.
Table 4 shows the $m_{s}$ values and martensite quantification of deformed specimens. The martensite volume fractions were calculated by methods 1 and 2 . It is interesting to show graphically how the martensite fraction increases with cold deformation, as presented in Figure 7.

Mathematically, the points can be fitted by sigmoidal curves with equations of type (Equation 3):

$C_{\alpha^{\prime}}=a \cdot \exp \left(-\exp \left(-k \cdot\left(x-x_{C}\right)\right)\right)$

Where $\mathrm{a}, \mathrm{k}$ and $\mathrm{x}_{\mathrm{c}}$ are constants of the model.

Two types of fitting were performed, as shown in Table 5 and exemplified in Figure 8 for method 2. The parameter a from Equation 3 means the maximum amount of martensite that can be formed, or the limit of martensite evolution. Theoretically, this corresponds to the austenite volume fraction present in the un-deformed specimen. One of the

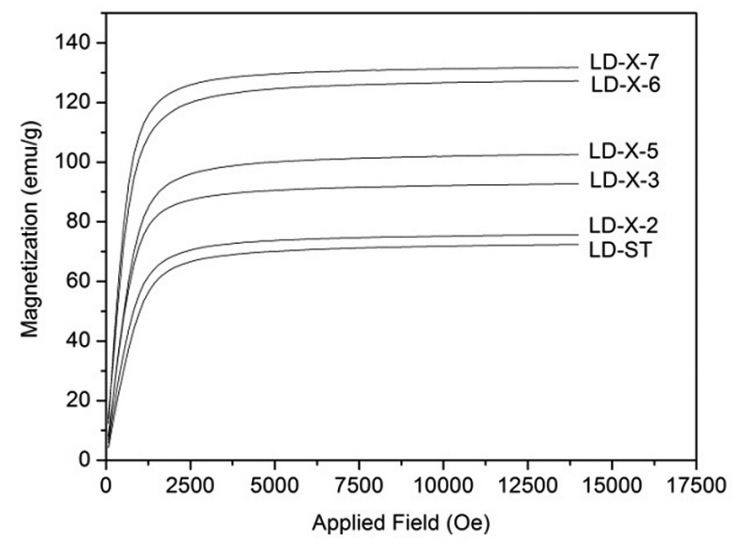

Figure 5. Magnetization curves of deformed specimens.

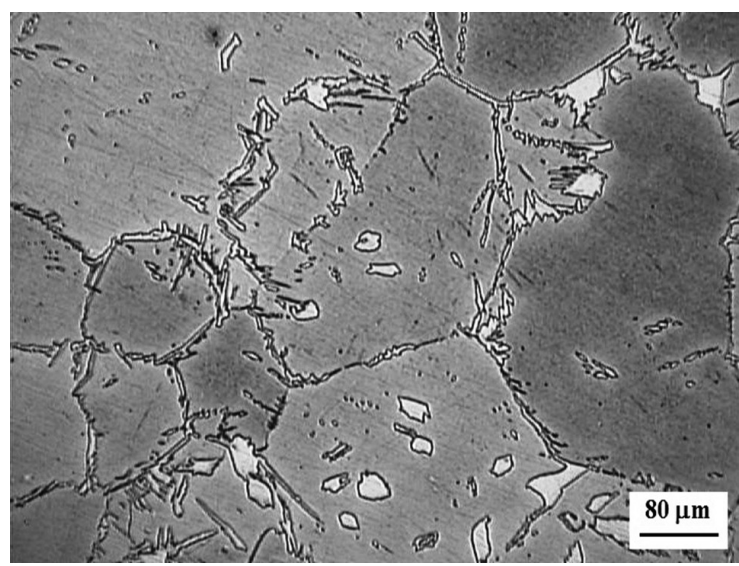

Figure 6. Microstructure of specimen LD-melt (as cast).

Table 3. Comparison between methods for quantification of $\mathrm{C} \delta$ (specimen LD-ST).

\begin{tabular}{ccc}
\hline Metallography & $\begin{array}{c}\text { Magnetism } \\
(\text { method } 1)\end{array}$ & $\begin{array}{c}\text { Magnetism } \\
(\operatorname{method} 2)\end{array}$ \\
\hline 0.52 & $C_{\delta}=\frac{70.8}{140.2}=0.505$ & $C_{\delta}=\frac{73.8}{140.8}=0.524$
\end{tabular}


Table 4. Martensite volume fractions determined by magnetic methods 1 and 2 .

\begin{tabular}{ccccc}
\hline Specimen & $\mathbf{m}_{\mathbf{s}}(\mathbf{m e t h o d} \mathbf{1})$ & $\mathbf{m}_{\mathbf{s}}(\mathbf{m e t h o d} 2)$ & $\mathbf{C}_{\alpha^{\prime}}(\operatorname{method} \mathbf{1})$ & $\mathbf{C}_{\alpha^{\prime}}(\mathbf{m e t h o d} 2)$ \\
\hline LD X-1 & 72.4 & 74.9 & 0.011 & 0.008 \\
LD X-2 & 73.6 & 76.8 & 0.020 & 0.021 \\
LD X-3 & 92.7 & 93.8 & 0.156 & 0.142 \\
LD X-4 & 97.7 & 98.9 & 0.192 & 0.178 \\
LD X-5 & 102.6 & 103.9 & 0.227 & 0.214 \\
LD X-6 & 127.3 & 128.7 & 0.403 & 0.390 \\
LD X-7 & 130.9 & 132.3 & 0.429 & 0.416 \\
LD X-8 & 131.9 & 133.0 & 0.436 & 0.421 \\
\hline
\end{tabular}

Table 5. Coefficients adjusted by fitting curves of $\mathrm{C}_{\alpha^{\prime}}$ versus deformation with Equation 3.

\begin{tabular}{cccccc}
\hline Magnetic method & Type of fitting & $\mathbf{a}$ & $\mathbf{k}$ & $\mathbf{x}_{\mathbf{c}}$ & $\mathbf{R}^{2}$ \\
\hline \multirow{2}{*}{1} & parameter a fixed & 0.4950 & 2.6295 & 0.4571 & 0.98679 \\
\multirow{2}{*}{2} & parameter a varied & 0.4462 & 3.4776 & 0.4077 & 0.99482 \\
& parameter a fixed & 0.4760 & 2.6686 & 0.4654 & 0.98957 \\
& parameter a varied & 0.4342 & 3.4156 & 0.4215 & 0.99563 \\
\hline
\end{tabular}

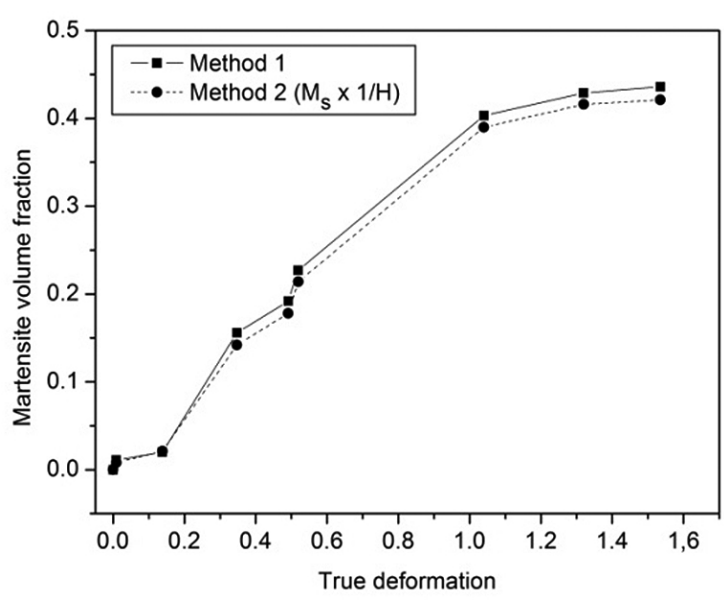

Figure 7. Martensite volume fraction as function of true deformation.

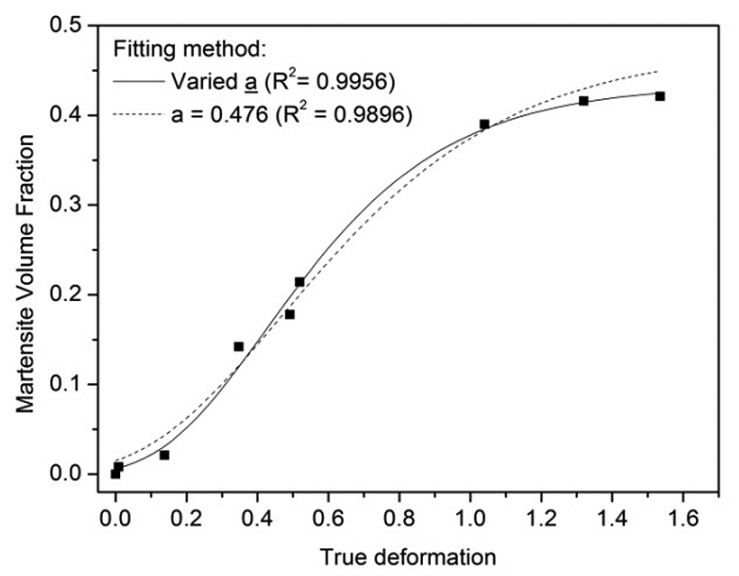

Figure 8. Curves of models for martensite volume fraction as function of true deformation.

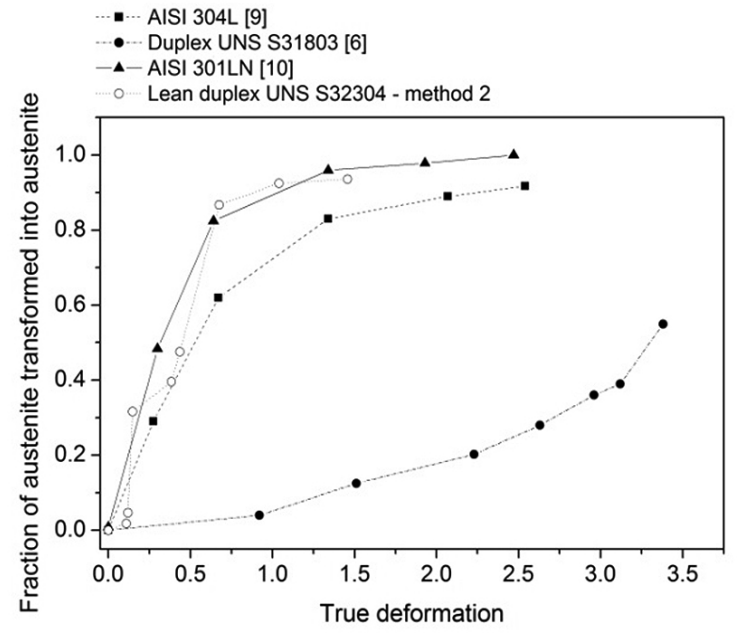

Figure 9. Comparison of austenite fraction transformed into martensite in different steels.

fittings was done by fixing the parameter "a" as the austenite volume fraction of the un-deformed specimen $(0.495$ for method 1 , and 0.476 for method 2). Although satisfactory correlation coefficients were obtained $\left(\mathrm{R}^{2}\right)$ by this way, it could be improved with fittings where the parameter "a" was varied for optimization, as showh in Table 5. The "a" values obtained were lower than the austenite volume fraction of the un-deformed specimen, which means that the total conversion of austenite into martensite by rolling at room temperature is not likely to occur in the alloy studied.

Finally, a comparison between the lean duplex stainless steel with duplex and metastable steels can be found in Figure 9. The austenite of lean duplex is much more metastable than the austenite of duplex steel ${ }^{5,6}$. The main differences of these two biphasic steels are the $\mathrm{Ni}$ and $\mathrm{Mo}$ 
content. For instance, the Mo of the steel studied is $0.22 \%$ and about $2.5 \%$ in duplex UNS S31803. The comparison of Figure 9 also allows to conclude that the lean duplex studied is more metastable than AISI 304L ${ }^{[11]}$ and almost as metastable as AISI 301LN ${ }^{[10]}$.

\section{Conclusions}

The metastability of austenite phase of UNS S32304 lean duplex steel was studied by means of magnetization saturation $\left(\mathrm{m}_{\mathrm{s}}\right)$ measurements. Two methods for $\mathrm{m}_{\mathrm{s}}$ determination from the magnetization curve were applied. In method 1 the last points of $\mathrm{M} \times \mathrm{H}$ curve were selected, a linear fit was performed, and the $\mathrm{m}_{\mathrm{s}}$ values were obtained by the extrapolation of the curve to $\mathrm{H}=0$. In method 2 , the $\mathrm{m}_{\mathrm{s}}$ values were obtained by the extrapolation of the $\mathrm{M} \times 1 / \mathrm{H}$

\section{References}

1. Seetharaman V and Krishnan R. Influence of the martensitic transformation on the deformation behaviour of an AISI 316 stainless steel at low temperatures. Journal of Materials Science. 1981; 16:523-530. http://dx.doi.org/10.1007/ BF00738646

2. Abreu HFG, Carvalho SS, Lima P N $N^{\circ}$, Santos RP, Freire VN, Oliveira Silva PM et al. Deformation induced martensite in an AISI 301LN stainless steel: characterization and influence on pitting corrosion resistance. Materials Research. 2007; 10(4):359-366. http://dx.doi.org/10.1590/ S1516-14392007000400007

3. Rocha MR and Oliveira CAS. Evaluation of the martensitic transformations in austenitic stainless steels. Materials Science and Engineering: A. 2009; 517:281-285. http://dx.doi. org/10.1016/j.msea.2009.04.004

4. Lo KH and Lai JK. On the cryogenic magnetic transition and martensitic transformation of the austenite phase of 7MoPLUS duplex stainless steel. Journal of Magnetism and Magnetic Materials. 2010; 322:2335-2339. http://dx.doi.org/10.1016/j. jmmm.2010.02.034

5. Reick W, Pohl M and Padilha AF. Determination of stacking fault energy of austenite in a duplex stainless steel. Steel Research International. 1996; 67:253-256. to $1 / \mathrm{H}=0(\mathrm{H} \rightarrow \infty)$. The results obtained by both methods were very close.

The evolution of austenite to martensite transformation could be modeled by sigmodal curves with high correlation coefficients.

The lean duplex steel UNS S32304 is much more susceptible to martensitic induced transformation than duplex UNS S31803, surely due to it's lower Ni and Mo contents. The austenite of lean duplex stainless steel was found to be as metastable as austenitic AISI 301LN grade, and more metastable than AISI 304L.

\section{Acknowledgements}

Authors acknowledge the Brazilian research agencies CAPES, CNPq, and FAPER for the financial support.

6. Tavares SSM, Silva MR, Pardal JM, Abreu HFG and Gomes AM. Microstructural changes produced by plastic deformation in the UNS S31803 duplex stainless steel. Journal of Materials Processing Technology. 2006; 180(1-3):318-322. http://dx.doi. org/10.1016/j.jmatprotec.2006.07.008

7. Lo KH, Lai JK, Shek CH and Li DJ.Effects of pre-treatment on the ac susceptibility and ageing behaviour of duplex stainless steels. Materials Science and Engineering: A. 2007; 452-453:78-86. http://dx.doi.org/10.1016/j.msea.2006.10.120

8. Cullity BD and Graham CD. Introduction to Magnetic Materials. Hoboken: John Wiley and Sons; 2009. PMid:19757932.

9. ASTM E-562-08 - Standard Test Method for Determining Volume Fraction by Systematic Manual Point Count, ASTM International, 2008.

10. Tavares SSM, Neto JM, Silva MR, Vasconcelos IF and Abreu HFG. Magnetic properties and a prime martensite quantification in an AISI 301LN stainless steel deformed by cold rolling. Materials Characterization. 2008; 59:901-904. http://dx.doi.org/10.1016/j.matchar.2007.07.007

11. Tavares SSM, Fruchart D, Neto JM, Miraglia S and Silva MR. Ferromagnetic properties of cold rolled AISI 304L steel. Journal of Magnetism and Magnetic Materials. 2001; 242-45:13911394. 